\title{
Where were you when President Kennedy was assassinated?
}

\author{
A. DANIEL YARMEY \\ University of Guelph, Guelph, Ontario, Canada NIG 2 WI \\ and \\ MAURICE P. BULL III \\ University of Tennessee, Knoxville, Tennessee 37916
}

\begin{abstract}
A total of 182 Americans and 215 Canadians were asked to remember what they were doing 12 years earlier when they learned that President John F. Kennedy had been assassinated. Subjects rated the clarity of these memories and their recollections for events which occurred close in time to this incident. Results showed that Canadians (84\% recall) remembered their activities equally as well as did the Americans (90\% recall). The only significant difference in stated recall between Americans and Canadians occurred in the reports of the youngest Americans (18-22 years) over their Canadian counterparts. No differences in clarity of recall were found among subjects for recollections of such contextual factors as place, time, or company. All subjects reported clearer memories for personal activities closest in time to learning of the critical event. However, respondents 23-27 years old, in contrast to younger and older subjects, suggested a decrement in clarity of memory for activities $1 \mathrm{~h}$ or more removed from the critical news event relative to their high clarity of recollection for activities at the moment of hearing about the assassination.
\end{abstract}

Canadians always have been either fascinated by or antagonistic toward their neighbor to the south. Being a neighbor to one of the most powerful countries in the world, Canadians by necessity are part of the American cultural and economic situation and often are keen observers of the American political scene. One public figure in particular who seems to have captured the interest of many Canadians is the late President of the United States, John F. Kennedy. The announcement on November 22, 1963 that the President had been shot was a shock which left an indelible impression on many of us, particularly on these two writers. Both of us have vivid memories of where we were and who we were with when we heard the news of the assassination. Apparently, our claims to a clear memory for these situational facts are not unique. The Toronto Daily Star surveyed a number of Canadian celebrities on November 21, 1975, 12 years after the assassination, and found that most of the respondents distinctly remembered what they were doing when they learned of the shooting. This newspaper report, which appeared in the midst of our planning to study these recollections, reinforced our belief that a systematic investigation of this phenomenon was warranted.

Requests for reprints should be sent to A. D. Yarmey, Department of Psychology, University of Guelph, Guelph, Ontario, Canada N1G 2W1. This research was supported by a grant from the National Research Council of Canada (AO228) to the first author. We wish to thank Laurie Hogg for her assistance.
The study of memory of personal experiences or of real-world events has been ignored by most research investigators and generally left to psychotherapists. The major reason for this neglect is the difficulty in verifying the accuracy of reports. Linton (1975) is currently performing a study in which she is her own subject and, therefore, can control what is learned and test what is retained over several years. Short of conducting such a study, it is difficult, if not impossible, to get the kind of data necessary to satisfy most investigators of memory.

It is usually impossible to distinguish whether or not our remote memories are accurate reconstructions or refabrications. This concern, however, with authenticity and accuracy of remote encodings is a theoretical problem which is not shared by all memory investigators (see Kvale, 1975; Meacham, 1972). Another way to conceptualize memory is to treat it as a belief system (Rozeboom, 1965) in which the individual acts as if his memories are real, and knows that different qualitative significance can be attached to these recollections. Whether or not these beliefs are accurate, that is, identical to the original perceptual encodings, is not an issue since he behaves in the present believing and accepting his recollections insofar as they are not contradictory to other evidence.

The purpose of this study was to investigate the stated clarity of subjects' recollections of their personal circumstances upon learning of the assassination of President Kennedy, 12 years after the event. It was expected that differences between Americans and 
Canadians would be found in favor of the Americans, but of more interest was the degree of similarity in reported recall for the two national groups at different age levels. We were interested in learning whether subjects would differ in their clarity of recall for the time of day they heard the critical news, the place they were, and who they were with at the time. In order to test for amnesia-like effects on a remote recollection, subjects were tested for their clarity of memory for activities 1,4 , and $24 \mathrm{~h}$ before and after learning of the shooting.

\section{METHOD}

\section{Subjects}

A total of 397 persons volunteered to serve as subjects; 182 lived at the time of testing in Tennessee and 215 lived in Ontario; 222 were male and 175 were female. The subjects were categorized into four arbitrary age levels: 60 Americans and 56 Canadians between 18 and 22 years; 51 Americans and 59 Canadians between 23 and 27; 58 Americans and 67 Canadians between 28 and 65 ; and 12 Americans and 32 Canadians 66 years and over. The majority of subjects were contacted in the University of Tennessee and the University of Guelph communities and were students, secretarial or support staff, faculty, or alumni. The rest were recruited through church groups, recreational centers, and senior-citizen clubs. Participation was voluntary and approximately $25 \%$ of the individuals contacted completed the questionnaire.

\section{Questionnaire}

Subjects were asked the following question: Can you recall what you were doing when you heard the news that President Kennedy had been shot? If subjects answered "Yes," they were asked to recollect and rate on a 5-point scale whether their memory was fuzzy, slight, moderate, clear, or very clear to each of the following questions: (1) Can you remember the time of day in which you heard the news that he had been shot? (2) Can you recall the place you were in? (3) Can you recall who you were with? (4) Can you recall what you were doing $1 \mathrm{~h}$ after you heard the news? (5) Can you recall what you were doing $1 \mathrm{~h}$ before you heard the news?

Identical questions were asked for $4 \mathrm{~h}$ and $24 \mathrm{~h}$ before and after learning of the shooting.

These questions formed part of a longer questionnaire dealing with recollections of both recent and remote memories which are separate from and independent of the focus of the present investigation. The serial arrangement of all pages of the questionnaire was randomized over all subjects, but the order of specific questions regarding the Kennedy assassination was constant for all participants. Subjects were permitted to complete the whole questionnaire at their own rate, which on the average took $15 \mathrm{~min}$.

\section{RESULTS}

Contrary to expectations, Americans did not differ significantly from Canadians in recollecting their activities at the moment of learning that President Kennedy had been shot $\left(\chi^{2}=2.53, \mathrm{df}=1, \mathrm{p}>.05\right)$. What is surprising, however, is the high percentage (90\% and $84 \%$, respectively) from both countries claiming this recollection. Males and females did not differ significantly on this recollection or on any of the questions raised in the survey. As you would expect, recollections varied over age groups. The analysis showed almost perfect recollections by all respondents in the 23-to-27. years category $(97.5 \%$ recall) and in the 28-to-65-years category ( $94.5 \%$ recall). Interestingly, every American subject $(\mathrm{N}=51)$ in the 23-27 age group claimed they could remember what they were doing. Relatively poorer recollections were reported by the youngest Americans (85\% recall) and youngest Canadians (66\% recall), and this difference was statistically significant $\left(\chi^{2}=3.85, \mathrm{df}=1, \mathrm{p}<.05\right)$. Similarly, senior citizens reported poor recollections of their activity, with only 6 of the 12 Americans claiming recall and 23 of the 32 (72\%) Canadians stating recall. This difference in mean scores, however, is not statistically significant.

Clarity of recollections for the time of day in which the subjects learned of the shooting, clarity of recall for the place the subject was, and clarity of remembering who the subject was with were similar for all subjects tested.

The analyses of recollections for activities 1,4 , and $24 \mathrm{~h}$ prior to and following the time of learning of the assassination showed greatest clarity of recall nearest in time to the critical event $[F(5,1700)=116.08, p<$ $.001]$. Relative to the other three age categories, subjects in the 23-to-27-year-old age group indicated the poorest clarity of recall $(\overline{\mathrm{X}}=1.90)$ for their activities before and after hearing of the assassination $[F(3,340)=4.50, p<.01]$. Note that this group reported the best clarity of recall among all age groups for their activities at the moment of hearing of the shooting. Mean recollections for activities before and after the assassination were $2.72,3.11$, and 2.61 , respectively, for the 18-to-22-year-olds, 28-65 group, and 66 and over group. All of these mean scores differed reliably $(\mathrm{p}<$ $.05)$ from the mean clarity score of the 23-to-27-year-old group, according to Duncan's range test.

\section{DISCUSSION}

The tendency to remember events of the distant past is dependent on the meaningfulness and relevance of the experience to the individual. Certain events, such as the memory of the assassination of President Kennedy, are resistant to decay presumably because of their consistent rehearsal through the mass media or from the salience of the event in the personal life of the individual. Other memories, such as one's activities or physical location during the occurrence of a highly significant event, are not rehearsed in the same manner as the event itself, yet they are remembered because they must form the context or background for such real-life events. This study demonstrates that the killing of President Kennedy was a significant event in the lives of both Canadians and Americans since the memory for contextual activities remained strong 12 years after the incident.

Memory is conceptualized in this study as a set of cognitive activities. It is probable that individuals differing in sex and age are distinguishable in a number of ways, both in their skill in using their cognitive processes and in what is remembered. In this study, however, males and females were 
found to give similar retrospective reports. Differences in memory among the four age groups are not surprising. It is likely that the reliable difference between the Americans and Canadians in the 18 -to-22-year age group ( $85 \%$ vs. $66 \%$ recall) reflects the attention that the American schools and family structure gave to an event which happened when the subjects were only 6-10 years old. In contrast to this very young age group, Canadians from 11 to 15 years old must have been politically aware of the importance of the event, since $95 \%$ of this group reported recalling their physical location when they heard of the shooting. The relatively poorer recall of the senior citizens in both countries may be related to a general decline in memory and performance and not related specifically to the Kennedy assassination.

This study did not specifically aim to describe the organizational and retrieval strategies employed in long-term memory, but two observations of this sort can be stated. First, subjects recalled more clearly events that occurred closest in time to the critical event. Second, clarity of recall of where a subject was when an event occurred, the time of day, and personal company, was accomplished equally well over all subject variables. It is likely that the above episodes are well-practiced markers from which inferences of memory are constructed. Inferences of events from the remote past often are made through logical reasoning, associative probabilities, and problem solving (see Whalen, 1965). One anomaly was found, however, in this study The highest percentage of recollections of personal activities on hearing of the Kennedy assassination was found in the 23-to-27-year group but this group claimed to have relatively poor recall of their activities 1 to $24 \mathrm{~h}$ before and after learning of the assassination. These amnesic-like results suggest that a narrowing of attention may occur in the presence of a highly traumatic episode which weakens the long-term clarity of reconstructions for other activities occurring close in time. This interpretation is not meant to suggest that the traumatic event was attended to and studied to the exclusion of all other episodes. Rather, the constant rehearsal of this event may have acted to maintain its memory strength and to minimize the spread of attention to other activities occurring close in time. Why this effect was found for this particular age group and not for the others is difficult to explain.

In sum, the survey of the Toronto Daily Star showing a high recollection for personal activities surrounding the assassination of President John F. Kennedy is not limited to public celebrities but includes many persons of adult age on both sides of the American-Canadian border. American presidents and, in particular, President Kennedy are international persons-their lives and deeds affect us all, both when in office and, apparently, in our memory.

\section{REFERENCES}

Kvale, S. Memory and dialectics: Some reflections on Ebbinghaus and Mao Tse-Tung. Human Development, 1975, 18, 205-222.

Linton, M. Memory for real-world events. In D. A. Norman \& D. E. Rumelhart (Eds.), Explorations in cognition. San Francisco: Freeman, 1975.

MeAcham, J. A. The development of memory abilities in the individual and society. Human Development, 1972, 15, 205-228.

Rozeвоом, W. W. The concept of "memory." Psychological Record, 1965, 15, 329-368.

Whalen, R. G. "Where were you the night of April 23, 1935?" In $\mathrm{R}$. S. Daniel (Ed.), Contemporary readings in general psychology (2nd. ed.). Boston: Houghton Mifflin, 1965.

(Received for publication October 31, 1977.) 